\title{
DESENVOLVIMENTO E NUTRIÇÃO DO CAPIM-TANZÂNIA EM FUNÇÃO DA APLICAÇÃO DE ZINCO
}

\section{DEVELOPMENT AND NUTRITION OF TANZANIA GRASS IN FUNCTION THE IMPLEMENTATION OF ZINC}

\author{
Amanda HERNANDES ${ }^{1}$ \\ Renato de Mello PRADO ${ }^{2}$ \\ Fabiana de Souza PEREIRA ${ }^{1}$ \\ Leandro Rosatto MODA ${ }^{1}$ \\ Juliana Garcia dos Santos ICHINOSE ${ }^{1}$ \\ Rita de Cássia Melo GUIMARÃES ${ }^{1}$
}

\begin{abstract}
RESUMO
Objetivou-se com este estudo avaliar os efeitos da aplicação de zinco no desenvolvimento e na nutrição do capimtanzânia. O delineamento experimental foi inteiramente casualizado, constituídos de seis doses de zinco $(0,15,30,60,120$ e $240 \mathrm{mg} \mathrm{dm}^{-3}$ ) e quatro repetições. Cada unidade experimental foi constituída de vaso preenchido com Latossolo Vermelho distrófico $\left(\mathrm{Zn}=0,4 \mathrm{mg} \mathrm{dm}{ }^{-3}\right)$. Foram realizados dois cortes, o primeiro após 53 dias da transplantação das mudas e o segundo 35 dias após o primeiro corte. Avaliou-se a concentração de zinco no solo, o teor de zinco foliar, o número de perfilhos, número de folhas, altura de plantas, massa seca da parte aérea, do sistema radicular e da planta inteira. As doses de zinco influenciaram a concentração de zinco no solo e na planta, e a produção de massa seca do capim-tanzânia, especialmente do primeiro corte. O capim-tanzânia apresenta alta tolerância à toxicidade de zinco, apresentando nível crítico tóxico de $273 \mathrm{mg} \mathrm{kg}^{-1}$.

Palavras-chave: Panicum maximum; fertilidade; micronutriente; nutrição; pastagem; solo.
\end{abstract}

\section{ABSTRACT}

It was aimed to assess the effects of zinc in the development and nutrition of Tanzania grass. The experimental design used was fully randomized, consisting of six doses of zinc $\left(0,15,30,60,120\right.$ and $\left.240 \mathrm{mg} \mathrm{dm}^{-3}\right)$ and four repetitions. The experimental unit was formed in a vase filled with a Red Latosol dystrophic $\left(\mathrm{Zn}=0.4 \mathrm{mg} \mathrm{dm}^{-3}\right)$. There were two cuts, the first after 53 days of transplanting seedlings and the second 35 days after the first cut. Was evaluated the concentration of zinc in the soil, the content of zinc leaf, the number of tillers, number of leaves, plant height, the dry mass of the shoot, root system and the whole plant. The doses of zinc influenced the concentration of zinc in soil and plant, and production of dry mass of Tanzania grass, especially the first cut. The Tanzania grass shows high tolerance to the toxicity of zinc, and toxic critical level of $273 \mathrm{mg} \mathrm{kg}^{-1}$.

Key-words: Panicum maximum; fertility; micronutrient; nutrition; pasture; soil

\footnotetext{
${ }^{1}$ Pós-Graduandos, Universidade Estadual Paulista "Júlio de Mesquita Filho" - Unesp, Faculdade de Ciências Agrárias e Veterinária (FCAV/ Unesp). Via de Acesso Prof. Paulo Donato Castellane s/n, Jaboticabal/SP, Brasil. CEP: 14.870-000. E-mail: amahernandes@hotmail.com; fabianadsp@hotmail.com; lerosattomoda@yahoo.com.br; jugarciaagro01@yahoo.com.br; rcmguimaraes@fafibe.br

2. Professor Doutor, Universidade Estadual Paulista "Júlio de Mesquita Filho" - Unesp, Departamento de Solos e Adubos, Faculdade de Ciências Agrárias e Veterinária (FCAV/Unesp). Bolsista PQ do CNPq. Via de Acesso Prof. Paulo Donato Castellane s/n, Jaboticabal/SP, Brasil. CEP: 14.870-000. E-mail: rmprado@fcav.unesp.br . Autor para Correspondência.
} 
HERNANDES, A. et al. Desenvolvimento e nutrição do capim-tanzânia...

\section{INTRODUÇÃO}

As pastagens são a principal fonte de alimento para o rebanho bovino no Brasil e são constituídas principalmente por gramíneas, destacando novas cultivares exigentes nutricionalmente, como o capim-tanzânia (Panicum maximum), o qual apresenta boa produtividade, qualidade e aceitabilidade pelos animais, proporcionando ganhos de peso elevados. As forragens de alta qualidade devem fornecer energia, proteína, minerais e vitaminas para atender a necessidade animal em pastoreio. Para a formação e a manutenção dos pastos, o fornecimento e o balanço de nutrientes na planta assumem importância fundamental, o que influencia diretamente na qualidade da forragem, sendo a prática da adubação indispensável para produtividade pastagens, destacando-se os micronutrientes, a exemplo do zinco.

O zinco é importante para o crescimento (Grewal et al., 1997) e para a manutenção da integridade da membrana plasmática da raiz (Cakmak \& Marschener, 1988) além de ser ativador enzimático de diversos processos metabólicos, como na síntese do triptofano que é precursor das auxinas responsáveis pelo crescimento de tecidos da planta (Mengel \& Kirkby, 1987), como também está diretamente envolvido no metabolismo do nitrogênio. Ademais, plantas carentes em zinco possuem diminuição no nível de RNA, resultando menor síntese de proteína e dificuldade na divisão celular (Malavolta et al., 1997), o que pode comprometer a qualidade da forragem.

A preocupação com o suprimento de zinco para cultivo de plantas forrageiras deve-se aos intensos relatos de baixos teores desse micronutriente em diversos solos do território brasileiro (Lopes \& Cox, 1977; Leon et al., 1985), sendo freqüentes as deficiências de zinco em solos de cerrados (Sousa et al., 1982; Magalhães et al., 2002; Vendrame et al., 2007) devido ao baixo teor do nutriente no material de origem, caracterizados pela baixa capacidade de troca catiônica e da atividade da argila, assim como a ocorrência de baixos teores de zinco nas forrageiras (Tebaldi et al., 2000).

De acordo com Graham \& Welch (1996), aproximadamente $50 \%$ dos solos usados para a produção de culturas no mundo são deficientes em zinco. No Brasil, a deficiência de zinco é relatada em várias culturas anuais (Barbosa Filho et al., 1994; Bataglia \& Raij, 1994; Galrão, 1994).

Outro fato é o manejo inadequado do solo, como a calagem excessiva, provocando diminuição na disponibilidade de zinco no solo (Fageria \& Zimmermann, 1979; Pessoa et al., 1994, Andreotti et al., 2001; Oliveira et al., 2003). Altas doses de fertilizante fosfatado podem, também, contribuir para a escassez de zinco devido ao antagonismo entre esses dois nutrientes (Fageria, 1984; Malavolta et al., 1997; Carneiro et al., 2008).

Em relação às plantas forrageiras, em alguns trabalhos objetivando avaliar a resposta do capim-tanzânia à aplicação de zinco não observouse efeitos na produção de massa seca das plantas em experimentos de campo (McLaren et al., 1991; Oliveira et al., 2000; Silva \& Coutinho, 2004), e em condições de vaso (Manarin, 2005). Os aspectos de toxicidade de zinco em forrageiras também são poucos conhecidos na literatura.

Assim, a adubação com zinco é importante para atender a exigência da forrageira, evitando prejuízos para o crescimento, desenvolvimento e, conseqüentemente, para a produção de biomassa.

Tendo em vista a escassez de informações na literatura sobre os efeitos do zinco em capimtanzânia, este trabalho teve como objetivo avaliar os efeitos de doses de zinco no desenvolvimento, na nutrição e na produção de massa seca do capim-tanzânia.

\section{MATERIAL E MÉTODOS}

O experimento foi conduzido em casa de vegetação da Faculdade de Ciências Agrárias e Veterinária - Unesp, Campus Jaboticabal, situada no município de Jaboticabal/SP, com coordenadas geográficas de $21^{\circ} 15^{\prime} \mathrm{S}$ de latitude e $48^{\circ} 18^{\prime} \mathrm{W}$ de longitude e altitude de $575 \mathrm{~m}$.

O delineamento experimental utilizado foi inteiramente casualizado, e os tratamentos consistiram de seis doses de zinco $(0,15,30,60$, 120 e $240 \mathrm{mg} \mathrm{dm}^{-3}$ ), aplicados na forma de sulfato de zinco, e quatro repetições, totalizando 24 vasos. Cada unidade experimental foi constituída por vaso com capacidade de $4 \mathrm{dm}^{3}$, preenchido com $3 \mathrm{dm}^{3}$ de amostras de um Latossolo Vermelho Distrófico, textura média (Embrapa, 2006), apresentando $\mathrm{pH}$ em $\mathrm{CaCl}_{2}=4,2 ;$ M.O. $=17 \mathrm{mg} \mathrm{dm}^{-3} ; \mathrm{P}=5 \mathrm{mg} \mathrm{dm}^{-3}$; $\mathrm{K}^{+}=0,5 \mathrm{mmol}_{\mathrm{c}} \mathrm{dm}^{-3} ; \mathrm{Ca}^{+2}=4 \mathrm{mmol}_{\mathrm{c}} \mathrm{dm}^{-3} ; \mathrm{Mg}^{+2}=2$ $\mathrm{mmol}_{\mathrm{c}} \mathrm{dm}^{-3} ;\left(\mathrm{H}^{+}+\mathrm{Al}^{+3}\right)=58 \mathrm{mmol}_{\mathrm{c}} \mathrm{dm}^{-3} ; \mathrm{SB}=6,5$ $\mathrm{mmol}_{\mathrm{c}} \mathrm{dm}^{-3} ; \mathrm{CTC}=64,5 \mathrm{mmol}_{\mathrm{c}} \mathrm{dm}^{-3} ; \mathrm{V}=10 \%$ e $\mathrm{Zn}$ $=0,4 \mathrm{mg} \mathrm{dm}^{-3}$.

Foi realizada a correção do solo pelo método da saturação por bases, com o objetivo de atingir $\mathrm{V}=70 \%$, considerado ideal para o capimtanzânia, segundo Raij et al. (1997), utilizando material corretivo com as seguintes características: $\mathrm{CaO}=585 \mathrm{~g} \mathrm{~kg}^{-1} ; \mathrm{MgO}=90 \mathrm{~g} \mathrm{~kg}^{-1} ; \mathrm{PN}=127 \%$; PRNT $=125 \%$. Após o período de incubação do solo (30 dias), foi realizada a adubação básica seguindo as indicações de Bonfim et al. (2004), aplicando-se $200 \mathrm{mg}$ de $\mathrm{K}^{+} \mathrm{dm}^{-3}$ (KCl p.a.), 1,2 mg de $\mathrm{Cu} \mathrm{dm}{ }^{-3}$ (CuSO $\mathrm{CH}_{2} \mathrm{O}$ p.a.), 0,8 mg de $\mathrm{B} \mathrm{dm}{ }^{-3}$ $\left(\mathrm{H}_{3} \mathrm{BO}_{3}\right.$ p.a. $), 1,5 \mathrm{mg}$ de $\mathrm{Fe} \mathrm{dm}{ }^{-3}\left[\mathrm{Fe}_{2}\left(\mathrm{SO}_{4}\right)_{3} \cdot 4 \mathrm{H}_{2} \mathrm{O}\right.$ p.a.], 3,5 mg de $\mathrm{Mn} \mathrm{dm}^{-3}\left(\mathrm{MnCl}_{2} \cdot 6 \mathrm{H}_{2} \mathrm{O}\right.$ p.a.) e 0,15 $\mathrm{mg}$ de $\mathrm{Mo} \mathrm{dm}$ ( $\mathrm{NaMoO}_{4} \cdot 2 \mathrm{H}_{2} \mathrm{O}$ p.a.). Foi aplicado também $305 \mathrm{mg}$ de $\mathrm{P} \mathrm{dm}{ }^{-3}$ na forma de superfosfato simples (Mesquita et al., 2004), assim como $300 \mathrm{mg}$ de $\mathrm{N} \mathrm{dm}^{-3}$ na forma de uréia, sendo parte aplicado 14 dias após a transplantação das mudas (100 mg de $\mathrm{N} \mathrm{dm}^{-3}$ ), e o restante $(200 \mathrm{mg}$ de $\mathrm{N} \mathrm{dm}$ ) aplicado aos 37 dias após a primeira aplicação de N.

A semeadura foi realizada em bandejas contendo areia como substrato e a transplantação das mudas de capim-tanzânia foi realizada no dia 
HERNANDES, A. et al. Desenvolvimento e nutrição do capim-tanzânia...

09/08/2007 com 7 dias após sua emergência, sendo que após 10 dias do transplantação foi realizado o desbaste, deixando-se apenas 5 plantas vaso ${ }^{-1}$. A irrigação dos vasos foi realizada de forma que a umidade do solo correspondesse a $60 \%$ da capacidade de retenção, utilizando-se água deionizada.

Aos 53 dias após a transplantação foi realizado o primeiro corte das plantas a $10 \mathrm{~cm}$ do solo, medindo-se também a altura das plantas com a ajuda de trena, do solo até a curvatura das folhas, e contando-se o número de perfilhos por planta. O segundo corte foi realizado rente ao solo, aos 35 dias após o primeiro corte, medindo-se novamente a altura das plantas e contando-se o número de perfilhos por planta que surgiram após o primeiro corte e também determinando a massa seca do sistema radicular. Assim, as plantas foram divididas em raízes, colmo e folhas no segundo corte, e, no primeiro corte, apenas em parte aérea. Depois, todo o material vegetal foi lavado em água destilada, seco em estufa com circulação forçada de ar à temperatura de 65 a $70^{\circ} \mathrm{C}$, até massa constante. A massa seca das partes da planta foi pesada, moída e utilizada para as determinações dos teores de zinco no tecido vegetal, seguindo a metodologia descrita por Bataglia et al. (1983). Por ocasião do segundo corte foi realizada a coleta de amostras de solo para a realização da análise química, para se determinar a concentração de zinco no solo (extrator DTPA), conforme metodologia descrita por Raij et al. (2001).

Os dados obtidos foram submetidos à análise de variância a partir do software Sistema de Análise Estatística - SANEST (Zonta et al., 1987). A análise de regressão foi aplicada para avaliar as doses de zinco utilizadas.

\section{RESULTADOS E DISCUSSÃO}

As doses de zinco aumentaram significativamente a concentração desse micronutriente no solo, conforme a equação de regressão $\hat{Y}=-5,61+0,49 x$, atingindo $120 \mathrm{mg}$ de $\mathrm{Zn} \mathrm{dm}{ }^{-3}$ (Figura 1). Essa concentração é considerada alta de acordo com a classificação de Raij et al. (1997), com correlação igual a $R^{2}=0,75^{\star *}$ entre as doses de zinco aplicada e o zinco determinado no solo, indicando a adequabilidade do DTPA na extração desse micronutriente, corroborando resultados de Natale et al. (2002, 2004). Silva \& Coutinho (2004), que trabalhando com capim-tifton, também observaram aumentos significativos de zinco no solo com a aplicação do nutriente.

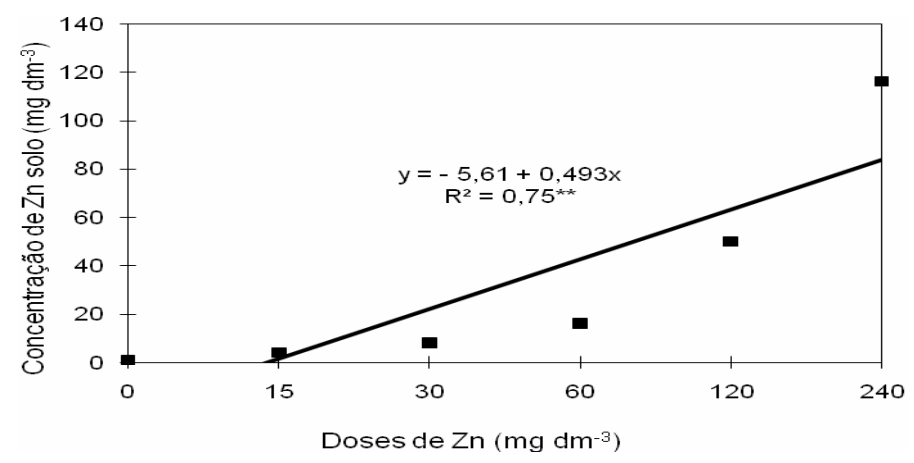

FIGURA 1 - Concentração de zinco no solo cultivado com capim-tanzânia em função das doses de zinco. **: significativo pelo teste $\mathrm{F}$ a $1 \%$ de probabilidade.

A recuperação do zinco foi de $49 \%$, valor esse superior ao obtido por Barman et al. (1998) que foi de $31 \%$, porém muito próximo aos valores obtidos por Natale et al. (2002), que foi de $47 \%$, e por Natale et al. (2004), que foi de $50 \%$, todos utilizando o mesmo extrator. Essa diferença pode ser devido ao fato da utilização de diferentes solos, onde espera-se que solos com baixa concentração de zinco apresentem alta probabilidade de resposta das plantas à aplicação desse micronutriente, e também se deve a diferenças no tempo de cultivo, pois a duração dos ensaios influencia as taxas de recuperação de zinco.

Esse incremento da concentração de zinco no solo refletiu no teor de zinco foliar, provocando aumento com ajuste quadrático no primeiro e segundo corte (Figura 2), conforme equações de regressão $\hat{Y}=29,44+0,948 x+0,0090 x^{2}$ e $\hat{Y}=$
$38,05+0,919 x+0,0059 x^{2}$, atingindo teores foliares de 603 e 728 mg de $\mathrm{Zn} \mathrm{kg}^{-1}$, respectivamente. Esses teores estão muito acima da faixa considerada adequada para gramíneas forrageiras do grupo do capim-tanzânia, que variam entre $15 \mathrm{e}$ $70 \mathrm{mg}$ de $\mathrm{Zn} \mathrm{kg}^{-1}$. Aparentemente, o capim-tanzânia deve possuir alta tolerância para concentrações elevadas de zinco no solo. Manarin (2005) também observou com a mesma forrageira incremento no teor foliar de zinco entre 21 e $728 \mathrm{mg}$ de $\mathrm{Zn} \mathrm{kg}^{-1}$ de massa seca, em função das doses de zinco aplicada no solo, corroborando outros autores (Kumar et al., 1985; Gupta, 1989; McLaren et al., 1991; Pessoa et al., 1994; Silva \& Coutinho, 2004). Entretanto Oliveira et al. (2000) não encontraram diferenças significativas no teor de zinco na parte aérea de capim-tanzânia e na exportação desse micronutriente com a aplicação de zinco ao solo. 
HERNANDES, A. et al. Desenvolvimento e nutrição do capim-tanzânia...

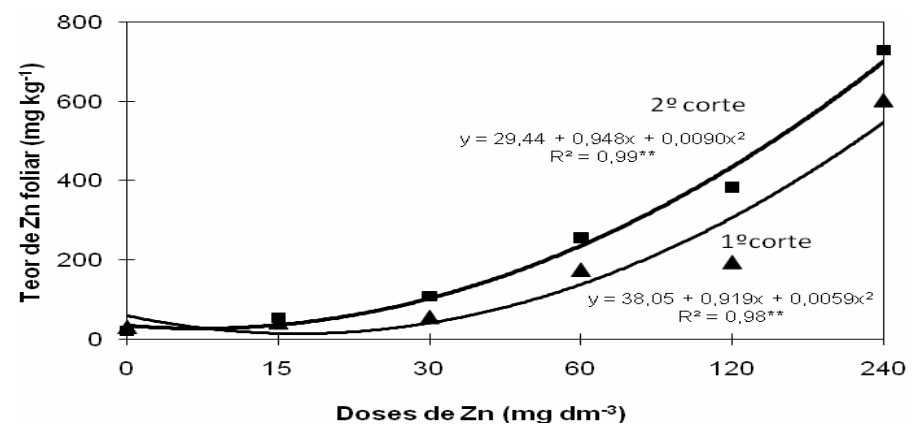

FIGURA 2 - Teor de zinco foliar em plantas capim-tanzânia no primeiro e no segundo corte em função das doses de zinco. ${ }^{*}$ : significativo pelo teste $\mathrm{F}$ a $1 \%$ de probabilidade.

No primeiro corte não ocorreram diferenças significativas para número de perfilhos (Figura 3a) e número de folhas do capim-tanzânia (Figura 3b) em função das doses de zinco aplicadas ao solo, diferindo significativamente apenas no segundo corte, onde houve aumento no número de perfilhos $(\hat{Y}=6,59+0,006 x)$ e no número de folhas ( $\hat{Y}=19,12+0,673 x)$ do capim-tanzânia em função

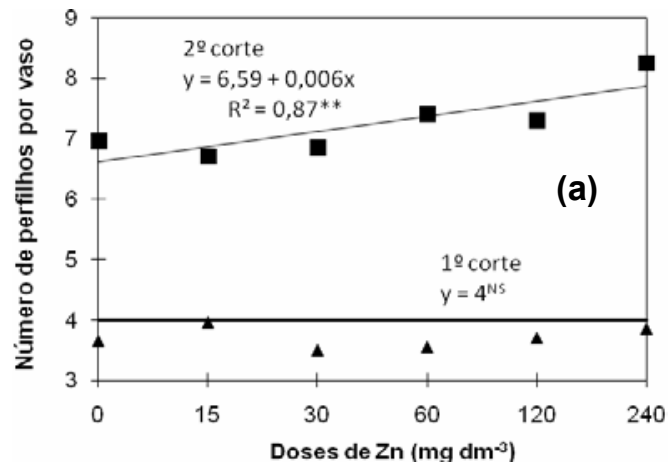

das doses de zinco aplicadas no solo. Oliveira et al. (2000) e Manarin (2005), trabalhando com doses de zinco no mesmo capim, não obtiveram diferenças significativas em nenhum dos cortes. $\mathrm{O}$ aumento no número de perfilhos e de folhas pode ser devido ao fato do zinco afetar a síntese e conservação de auxinas, hormônios vegetais responsáveis pelo crescimento da planta.

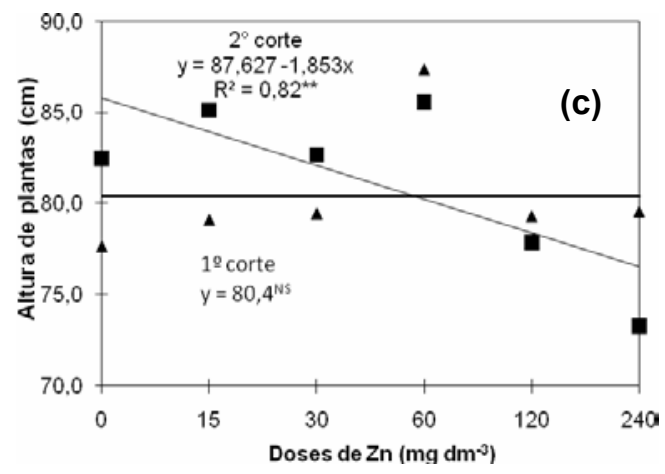

FIGURA 3 - Número de perfilhos por vaso (a), número de folhas por vaso (b) e altura de plantas (c) em capimtanzânia em função das doses de zinco. **: significativo pelo teste $\mathrm{F}$ a $1 \%$ de probabilidade; NS= não signficativo. 
HERNANDES, A. et al. Desenvolvimento e nutrição do capim-tanzânia...

Para a altura de plantas do capimtanzânia, não ocorreu diferença significativa para as doses de zinco no primeiro corte (Figura 3c), assim como observado por Oliveira et al. (2000). Já no segundo corte, houve diminuição significativa da altura de plantas. Em doses elevadas, o zinco pode proporcionar diminuição no crescimento das plantas por inibir competitivamente a absorção de $\mathrm{Ca}$ e $\mathrm{Mg}$, nutrientes que limitam o adequado crescimento das plantas (Malavolta et al., 1997). Lima et al. (2000), trabalhando com nutrientes em gramíneas forrageiras, constataram que a omissão de micronutrientes, incluindo o zinco, promoveu redução do crescimento de plantas assim como do perfilhamento, o que não ocorreu com trabalhos de Faquin et al. (1995, 1998) e Morikawa et al. (1998).

No primeiro corte houve aumento da massa seca da parte aérea do capim-tanzânia em função da dose de zinco aplicada no solo (Figura 4a) conforme a equação de regressão $\hat{Y}=19,47+$

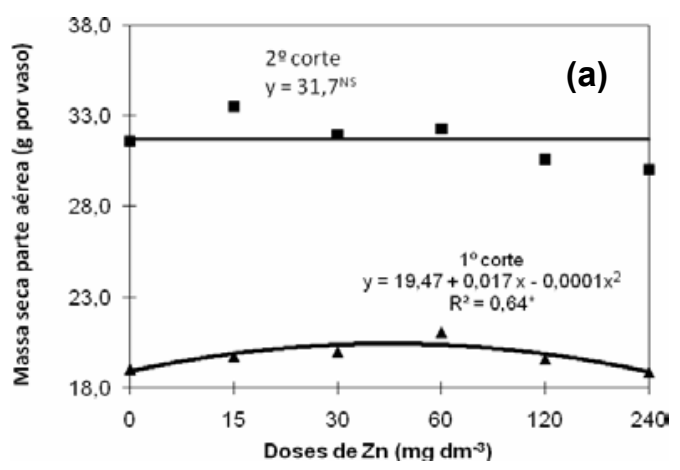

FIGURA 4 - Massa seca da parte aérea (a) e da planta inteira (b) em capim-tanzânia em função das doses de zinco. *: significativo pelo teste $\mathrm{F}$ a $5 \%$ de probabilidade; NS= não significativo.

No segundo corte não ocorreu diferença significativa para massa seca da parte aérea, como observado por Gupta (1989), McLaren et al., (1991), Oliveira et al. (2000), Silva \& Coutinho (2004), Yagi et al. (2006) e Santos et al. (2009) trabalhando com de zinco em forrageiras. Entretanto Pessoa et al. (1994), trabalhando com doses de zinco em capimpensacola, constataram uma redução no rendimento de massa seca com aplicação de zinco em relação à testemunha; porém, esse fato foi relacionado ao baixo valor de $\mathrm{pH}$ do solo na ocasião, o que aumentou a disponibilidade do zinco às plantas, prejudicando o seu desenvolvimento. $A$ falta de resposta à aplicação de zinco pode ser devido à sua alta concentração média na testemunha, que foi de $38,05 \mathrm{mg} \mathrm{kg}^{-1}$ no primeiro corte e $29,44 \mathrm{mg} \mathrm{kg}^{-1}$ no segundo corte, já que relatos na literatura demonstram que apenas teores inferiores a $25 \mathrm{mg} \mathrm{kg}^{-1}$ caracterizam deficiência do elemento nas folhas (Furlani, 2004; Fernandes, 2006). Apesar de presente em pequenas concentrações no solo, o elemento encontrou-se
$0,017 x-0,0001 x^{2}$, sendo que a dose que proporcionou $90 \%$ da produção máxima de massa seca foi a de $100 \mathrm{mg} \mathrm{dm}^{-3}$, correspondendo ao teor foliar de $189 \mathrm{mg}$ de $\mathrm{Zn} \mathrm{kg}{ }^{-1}$. Esse aumento na massa seca pode ser devido ao efeito do zinco na nutrição da planta atuando como ativador enzimático de diversos processos metabólicos, pois em plantas deficientes em zinco, tem-se, em geral, acúmulo de aminoácidos, diminuição da síntese de proteínas associadas à diminuição das auxinas, decrescendo assim a produção de massa seca. Kawatoko et al. (2000), trabalhando com adubação de zinco em Brachiaria decumbens, e Kumar et al. (1985) com milheto, observaram aumento na produção de massa seca com a utilização da adubação com zinco. Entretanto, outros autores não observaram efeito do zinco na produção de massa seca em experimentos de campo (McLaren et al., 1991; Oliveira et al., 2000; Silva \& Coutinho, 2004), e em condições de vaso (Manarin, 2005).

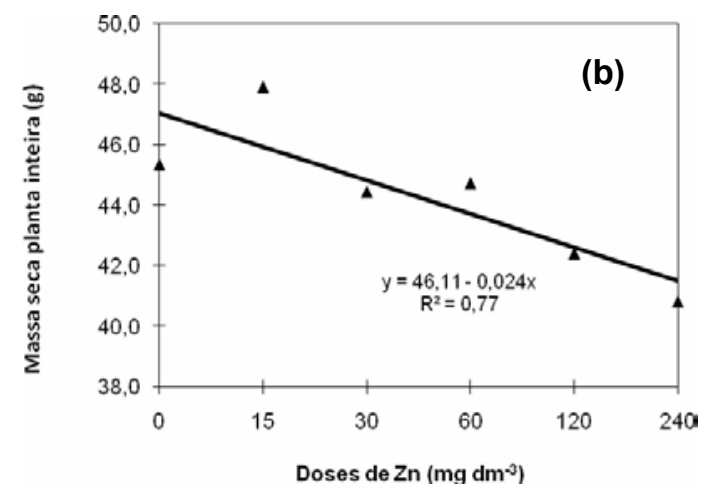

em forma disponível e suficiente para suprir a necessidade das plantas.

Assim como ocorreu com Manarin (2005), em capim-tanzânia, o segundo corte apresentou produção de massa seca da parte aérea superior a do primeiro corte. Isto pode ser explicado porque na fase de estabelecimento a planta está estruturando a parte aérea e formando raízes, e, no segundo crescimento, a planta já estabelecida, pode utilizar os compostos e a energia para o crescimento.

Já para a massa seca do sistema radicular, não ocorreu diferença significativa para as doses de zinco aplicadas, com média de $12,89 \mathrm{~g} \mathrm{vaso}^{-1}$, porém, para a massa seca da planta inteira do capim-tanzânia houve diferença significativa (Figura $4 b)$ conforme a equação de regressão $\hat{Y}=46,11$ $0,024 x$, a qual diminuiu com 0 incremento das doses de zinco aplicadas no solo. A toxicidade por zinco demonstrou ser mais prejudicial à raiz que à parte aérea, sendo que a dose de $120 \mathrm{mg}$ de $\mathrm{Zn}$ $\mathrm{dm}^{-3}$ proporcionou $50 \%$ de diminuição na produção de massa seca, correspondendo ao teor foliar de 
HERNANDES, A. et al. Desenvolvimento e nutrição do capim-tanzânia...

$273 \mathrm{mg}$ de $\mathrm{Zn} \mathrm{kg}{ }^{-1}$, tanto no primeiro e no segundo corte. Os níveis críticos tóxicos de zinco na cultura de arroz, milho e trigo são, respectivamente, 673 $\mathrm{mg} \mathrm{kg}^{-1}, 427 \mathrm{mg} \mathrm{kg}^{-1}$ e $100 \mathrm{mg} \mathrm{kg}^{-1}$ (Fageria, 2000), indicando que o capim-tanzânia, com nível crítico tóxico observado de $273 \mathrm{mg}$ de $\mathrm{Zn} \mathrm{kg}^{-1}$, é mais tolerante à toxidez de zinco apenas quando comparado ao trigo.

\section{CONCLUSÕES}

As doses de zinco aumentaram a concentração de zinco no solo e na planta, porém diminuiu a produção de massa seca do capimtanzânia, especialmente do primeiro corte. O capimtanzânia apresenta alta tolerância à toxicidade de zinco, indicando possuir nível crítico tóxico de 273 $\mathrm{mg} \mathrm{kg}^{-1}$.

\section{REFERÊNCIAS}

1. ANDREOTTI, M; SOUZA, E. C. A; CRUSCIOL, C. A. C. Componentes morfológicos e produção de matéria seca de milho em função da aplicação de calcário e zinco. Scientia Agricola, v. 58, n. 2, p. 321-327, 2001.

2. BARBOSA FILHO, M. P.; DYNIA, J. F.; FAGERIA, N. K. Zinco e ferro na cultura do arroz. Brasília: EMBRAPA-SPI, 1994. 71 p. (EMBRAPA - CNPAF. Documentos, 49).

3. BARMAN, K. K.; GANESHAMURTHY, A. N.; TAKKAR, P. N. Zinc requeriment of soybean (Glycine max) - wheat (Triticum aestivum) cropping sequence in some swell-shrink soils. Indian Journal of Agricultural Science, v. 68, n. 12, p. 759-761, 1998.

4. BATAGLIA, O. C. et al. Métodos de análise química de plantas. Campinas: Instituto Agronômico, 1983. 48 p. (Boletim Técnico, 78).

5. BATAGLIA, O. C.; RAIJ, B. van. Soluções extratoras na avaliação da fitodisponibilidade do zinco em solos. Revista Brasileira de Ciência do Solo, v. 18, n. 3, p. 457-461, 1994.

6. BONFIM, E. M. S. et a.. Níveis críticos de fósforo para Brachiaria brizantha e suas relações com características físicas e químicas em solos de Pernambuco. Revista Brasileira de Ciência do Solo, v. 28, n. 2, p. 281-288, 2004.

7. CAKMAK, I.; MARSCHNER, H. Increase in membrane permeability and exudation in roots of zinc deficient plants. Journal of Plant Physiology, v. 132, n. 3, p. $356-361,1988$.

8. CARNEIRO, L. F. et al. Fontes, doses e modos de aplicação de fósforo na interação fósforo-zinco em milho. Ciência e Agrotecnologia, v. 32, n. 4, p.1133-1141, 2008.

9. EMBRAPA. Centro Nacional de Pesquisa de Solos. Sistema brasileiro de classificação de solos. 2. ed. Rio de Janeiro: Embrapa Solos, 2006. 306 p.

10. FAGERIA, N. K. Adubação e nutrição mineral da cultura de arroz. Rio de Janeiro: Campus, 1984. 341 p.

11. FAGERIA, N. K. Níveis adequados e tóxicos de zinco na produção de arroz, feijão, milho, soja e trigo em solo de cerrado. Revista Brasileira de Engenharia Agrícola e Ambiental, v. 4, n. 3, p. 390-395, 2000.

12. FAGERIA, N. K.; ZIMMERMANN, F. J. P. Interação entre fósforo, zinco e calcário em arroz de sequeiro. Revista Brasileira de Ciência do Solo, v. 3, n. 2, p. 88-92, 1979.

13. FAQUIN, V. et al. Limitações nutricionais para gramíneas forrageiras em Cambissolo álico da microrregião Campos da Mantiqueira-MG, Brasil. 2. Nutrição em macro e micronutrientes. Pasturas Tropicales, v. 17, n. 3, p. 17-22, 1995.

14. FAQUIN, V. et al. Nutrição em macro e micronutrientes de gramíneas forrageiras cultivadas em Latossolo da região dos Campos das Vertentes-MG, Brasil. Pasturas Tropicales, v. 20, n. 2, p.13-19, 1998.

15. FERNANDES, M. S. Nutrição mineral de plantas. Viçosa: Sociedade Brasileira de Ciência do Solo, 2006. 432 p.

16. FURLANI, A. M. C. Nutrição mineral. In: KERBAUY, G. B. (Ed.) Fisiologia vegetal. Rio de Janeiro: Guanabara Koogan, 2004. p. 40-75.

17. GALRÃO, E. Z. Métodos de correção da deficiência de zinco para o cultivo do milho num Latossolo Vermelho-Escuro argiloso sob cerrado. Revista Brasileira de Ciência do Solo, v. 18, n. 2, p. 229-233, 1994.

18. GRAHAM, R. D.; WELCH, R. M. Breeding for staple food crops with high micronutrient density. Washington: International Food Policy Research Institute, 1996. 73 p. (IFPRI. Working Papers on Agricultural Strategies for Micronutrients, 3.)

19. GREWAL, H. S.; ZHONGGU, L.; GRANHAN, R. D. Influence of subsoil zinc on dry matter production, seed yield and distribution of zinc in oilseed rape genotypes differing in zinc efficiency. Plant and Soil, v. 192, n. 2, p. 181-189, 1997.

20. GUPTA, U. C. Effect of zinc fertilization on plant zinc concentration of forages and cereals. Canadian Journal of Soil Science, v.69, n. 3, p.473-479, 1989.

21. KAWATOKO, M.; ISEPON, O. J.; FERNANDES, F. M. Efeito da aplicação de calcário, nitrogênio e zinco sobre a produção e valor nutritivo de Brachiaria decumbens em solo de cerrado. In: XXXVII REUNIÃO ANUAL DA SOCIEDADE BRASILEIRA DE ZOOTECNIA, 37, 2000, Viçosa. Anais eletrônicos... Viçosa: SBZ, 2000. Disponível em: <http:// www.sbz.org.br/2007/internas/cds_e_anais.html >. Acesso em: 27 nov. 2008.

22. KUMAR, V.; AHLAWAT, V. S.; ANTIL, R. S. Interactions of nitrogen and zinc in pearl millet: 1. Effect of nitrogen and zinc levels on dry matter yield and concentration and uptake of nitrogen and zinc in pearl millet. Soil Science, v. 39, n. 4, p. 351-356, 1985.

23. LEON, L.A.; LOPES, A. S.; VLEK, P. L. G. Micronutrient problems in tropical Latin America. Fertilizer Research, v. 7, n. 1-3, p. 95-129, 1985.

24. LIMA, D. V. et al. Macro e micronutrientes no crescimento do braquiarão e da soja em latossolos sob cerrado da região de Cuiabá - MT. Ciência e Agrotecnologia, v. 24, n. 1, p. 96-104, 2000.

25. LOPES, A. S.; COX, F. R. A survey of the fertility of surfaces soils under "Cerrado" vegetation in Brazil. Soil Science Society of America Journal, v. 41, n. 4, p. 742-747, 1977.

26. MAGALHÃES, R. T.; OLIVEIRA, I. P.; KLIEMANN, H. J. Relações da produção de massa seca e as quantidades de nutrientes exportados por Brachiaria brizantha em solos sob o manejo pelo sistema "barreirão". Pesquisa Agropecuária Tropical, v.32, n. 1, p.13-20, 2002.

27. MALAVOLTA, E.; VITTI, G.C.; OLIVEIRA, S. A de. Avaliação do estado nutricional das plantas: princípios e aplicações. 2.ed. Piracicaba: POTAFOS, 1997. $319 \mathrm{p}$.

28. MANARIN, S. A. Combinações de doses de fósforo e de zinco em solução nutritiva para o capim-Tanzânia. 2005. 
HERNANDES, A. et al. Desenvolvimento e nutrição do capim-tanzânia...

68 p. Dissertação (Mestrado em Agronomia) - Escola Superior de Agricultura Luiz de Queiroz, Universidade de São Paulo, Piracicaba, 2005.

29. McLAREN, R. G.; McLENAGHEN, R. D.; SWIFT, R. S. Zinc applications to pastures: effect on herbage and soil zinc concentrations. New Zealand Journal of Agricultural Research, v. 34, p.113-118, 1991.

30. MENGEL, K.; KIRKBY, E. A. Principles of plant nutrition. 2. ed. Bern: International Potash Institute, 1987. 536 p.

31. MESQUITA, E. E. et al. Teores críticos de fósforo em três solos para o estabelecimento de capim-Mombaça, capimMarandu e capim-Andropogon em vasos Revista Brasileira de Zootecnia, v. 33, n. 2, p. 290-301, 2004

32. MORIKAWA, C. R. et al. Crescimento e produção de gramíneas forrageiras em amostras de Latossolo da região dos Campos das Vertentes-MG, Brasil. Pasturas Tropicales, v. 20, n. 2, p. 19-23, 1998.

33. NATALE, W. et al. Resposta de mudas de goiabeira à aplicação de zinco. Revista Brasileira de Fruticultura, v. 24, n. 3, p. 770-773, 2002.

34. NATALE, W. et al. Efeitos da aplicação de zinco no desenvolvimento, no estado nutricional e na produção de matéria seca de mudas de maracujazeiro. Revista Brasileira de Fruticultura, v. 26, n. 2, p. 310-314, 2004.

35. OLIVEIRA, I. P. et al. Efeitos qualitativo e quantitativo de aplicação do zinco no capim Tanzânia. Pesquisa Agropecuária Tropical, v. 30, n. 1, p. 43-48, 2000.

36. OLIVEIRA, S. C. et al. Resposta de duas cultivares de arroz a doses de zinco aplicado como oxissulfato. Pesquisa Agropecuária Brasileira, v. 38, n. 3, p. 387-396, 2003.

37. PESSOA, A. C. S. et al. Efeito do calcário, do fósforo e do zinco no rendimento de pensacola. Ciência Rural, v. 24, n. 1, p. 35-39, 1994.

38. RAIJ, B. van et al. Análise química para avaliação da fertilidade de solos tropicais. Campinas: Instituto Agronômico, 2001. $285 \mathrm{p}$.

39. RAIJ, B. van et al. Recomendações de adubação e calagem para o Estado de São Paulo. 2.ed.rev.atual. Campinas: Instituto Agronômico, 1997. 285 p.

40. SANTOS, H. C. et al. Cu e Zn na cultura do sorgo cultivado em três classes de solos. I. Crescimento vegetativo e produção. Revista Brasileira de Engenharia Agrícola e Ambiental, v. 13, n. 2, p. 125-130, 2009.

41. SILVA, A. R.; COUTINHO, E. L. M. Adubação com nitrogênio e zinco para o capim-Tifton 85: efeitos no solo e na planta em sucessivos crescimentos. Científica, v. 32, n. 1, p. 65-74, 2004

42. SOUSA, J. C.; CONRAD, J. H.; MOTT, G. O.; McDOWELL, L. R; AMMERMAN, C. B; BLUE, W. G. Inter-relações entre minerais no solo, plantas forrageiras e tecido animal no norte de Mato Grosso. 4. Zinco, magnésio, sódio e potássio. Pesquisa Agropecuária Brasileira, v.17, n.1, p.11-20, 1982.

43. TEBALDI, F. L. H. et al. Composição mineral das pastagens das regiões Norte e Noroeste do Estado do Rio de Janeiro: 2. Manganês, ferro, zinco, cobre, cobalto, molibdênio e chumbo. Revista Brasileira de Zootecnia, v. 29, n. 2, p. 616$629,2000$.

44. VENDRAME, P. R. S. et al. Disponibilidade de cobre, ferro, manganês e zinco em solos sob pastagens na Região do Cerrado. Pesquisa Agropecuária Brasileira, v. 42, n. 6, p. 859-864, 2007.

45. YAGI, R. et al. Aplicação de zinco via sementes e seu efeito na germinação, nutrição e desenvolvimento inicial do sorgo. Pesquisa Agropecuária Brasileira, v. 41, n. 4, p. 655-660, 2006

46. ZONTA, E. P.; MACHADO, A. A.; SILVEIRA JUNIOR, P. Sistema de análise estatística para microcomputadores: manual de utilização. 2.ed. Pelotas: UFPel, 1987. 17 pp.

Recebido em 06/01/2009 Aceito em 29/07/2009 
